\title{
A Review of a Distributed High Performance Computing Implementation
}

\author{
Joe Flanagan ${ }^{\mathrm{a}}$, Gareth Huw Davies ${ }^{\mathrm{a} *}$, Frederic Boy ${ }^{\mathrm{ab}}$ and Daniele \\ Doneddu $^{\mathrm{a}}$
}

${ }^{a}$ School of Management, Swansea University, Swansea, United Kingdom; ${ }^{b}$ Department of Biomedical Engineering, University College London, London, United Kingdom

*Swansea University, Fabian Way, Swansea, SA1 8EN, g.h.davies@swansea.ac.uk Orcid 0000-0001-7872-7574

\section{Abstract}

This paper presents the case of a regional government and academia working together to realise High Performance Computing Wales, a shared supercomputing infrastructure. The initiative aimed to support economic development through creation of a distributed supercomputing capability, a skills development programme, and an initial programme of collaborative research and innovation.

From the perspective of Smart Specialisation, the study examines whether the economic development ambitions were achieved, and adds to the limited literature reviewing this aspect of High Performance Computing Centres. Using principles of public sector investment guidelines, the study presents for Smart Specialisation theory that such facilities can provide a general purpose technology. Further, from the perspective of practitioners, it highlights important steps in the appraisal, monitoring and evaluation of such initiatives. 


\section{Introduction}

The role of technology in supporting economic development is well-recognised (Malecki, 1997), along with its contribution to overall national productivity (Hanna 1993) (Galán-Muros, van der Sijde et al., 2017), in nations both developed (Matteucci, O'Mahony et al., 2005) and developing (Indjikian and Siegel, 2005). At an industry level, 'Computerisation’ has also been shown to support increased productivity, with impact developing over time (Brynjolfsson and Hitt, 2003).

Relating to endogenous growth theory, the potential for knowledge-based technology sectors to support economic development has been an interest for the post-industrial region of south Wales, through actions of its regional government (Cooke and Leydesdorff, 2006). Welsh Government has targeted technology sectors to support innovation, including through collaboration between industry and academia, with digital technologies as an important enabler (WAG, 2004). These endeavours included High Performance Computing (HPC) initiatives such as the Health and Bio-Informatics capabilities centred around the Institute of Life Science (ILS) at Swansea University (Abbey et al., 2008). Such an approach is captured within the more recent concept of Smart Specialisation, including the role of infrastructure to support regional economic development (Sarkar et al., 2020).

The importance of High Performance Computing (HPC), or Supercomputing, to industrial competitiveness has been highlighted over many years by governments (EU, 2015; Holdren, 2016), scholars (Aldag, 1989; Mowery and Rosenberg, 1989) and other agencies (Ezell and Atkinson, 2016; EIB, 2018). A long-established systems 'armsrace' has continued with technology vendors and nations competing to develop ever more powerful systems to address problems of increasing complexity. The importance of leadership in the field is often discussed in terms of national security and 
competitiveness, even to the extent of governments such as in the US establishing laws to ensure its ongoing development (Compete, 2015) and control dissemination of technology to other nations (Johnston, 1998; McLoughlin and Fergusson, 2003). In parallel, the importance of skills to support and expand the user base has been highlighted (Mcnamara, 1987; EU, 2015).

Despite notable specialist applications, Dongarra and Van der Steen (2012) describe how the convergence of HPC and desktop hardware and software has led to HPC no longer being an isolated niche as it was in the 1970s. This includes the recent significant increases in x86-based (dominant standard for desktop/laptop processors) systems supporting broader academic and industrial use of HPC in research and development (Strohmaier, Dongarra et al., 2005). Commoditisation and standardisation of computing resources through a common chipset architecture has allowed some software to transcend high performance and desktop systems. This phenomenon is becoming increasingly important with the emergence of Internet of Things and associated technology distributing significant computing power (Raisinghani, 2015), as well as for other data-intensive concepts such as Smart Cities (Samih, 2019). However, while technology has advanced hugely since the advent of HPC, the scale of skills development efforts has been more limited (Bell and Gray, 2002; EU, 2015). National research facilities, such as those at Daresbury and Edinburgh in the United Kingdom provide foci for powerful public sector civilian systems. This reflects a noted trend in concentration of the most performant systems in fewer centres (Strohmaier, Dongarra et al., 1999), with regions around the world wanting to host major systems (EU, 2015; Holdren, 2016).

The high capital investment and running costs of HPC infrastructure have been a factor leading to the development of distributed and shared infrastructure, making pooled 
resources available across wider communities. Shared infrastructures have been established across geographies which are multinational (e.g. Partnership for Advanced Computing in Europe - PRACE), national (e.g. WestGrid in Canada) and regional (e.g. HPCW), though primarily centred on universities and other public research organisations.

As Etzkowitz (1998) noted in the late 1990s, centralisation and proximity of such tools was becoming less important as Information and Communications Technology made them more accessible remotely. This reflects the more recent concept of 'cloud' solutions which has become prevalent in computing (Armbrust, Fox et al., 2010), including for how it can make computation services more accessible to Small and Medium-sized Enterprises (SMEs) (Sultan, 2011). Models of cloud solutions, together with challenges of interoperability are described by Dillon, Wu et al. (2010), while flexibility, shared cost-base and availability provide potential advantages, particularly to SMEs (Sultan, 2011). Such advantages align with the objective of European Union policy-makers to make computation infrastructure more accessible to SMEs (EU, 2015), in part by addressing the challenges of infrastructure costs (EIB, 2018).

\section{$\underline{\text { HPC 'Centres', Outreach and Economic Development }}$}

The aforementioned increasing importance of HPC has led to the formation of international, national and regional (Rončević, Coscodaru et al., 2019) strategies to secure long-term investment, often with echoes of Smart Specialisation focus (Foray, 2014), aiming to leverage regional aligned academic and industrial strengths. In this context, HPC plays an important role in innovation across a broad range of sectors. While sectors and applications may vary, commonalities amongst them are increasing complexity, greater volumes of data and growing computational requirements. Notably, smart specialisations within Wales reflect a number of computationally intensive 
sectors, including health and bio-informatics, energy systems, automotive engineering and semiconductor technologies (EU, 2017).

The importance of HPC-relevant sectors to the broader economy has received much attention as noted earlier, however the role and importance of individual centres has limited structured consideration. Exceptions where the impact of specific centres has been studied include major facilities in North Carolina (Lee and Christensen, 1990) and Pittsburgh (PSC, 2011). The latter, more recent Pittsburgh study emphasises the considerable indirect and induced economic impacts of the facility. The study suggested some 1,666 jobs across the region are supported by the centre’s activities. This observation is noteworthy as it suggests a significant proportion of facility impact is delivered through its users and partners rather than being found at the centre itself. Elsewhere, a study of a 2007 Korean initiative providing HPC services to SMEs reported significant impact. This was across a broad range of benefits, with a calculated return on investment of 10:1 (Kim, Lee et al., 2010), including both direct and indirect impacts, as per the Pittsburgh case (PSC, 2011).

Potential to replicate these benefits led to the Welsh Government and other regional stakeholders establishing the High Performance Computing Wales (HPCW) initiative. An existing regional HPC centre at the Swansea-based Institute of Life Science demonstrated a level of success within the smart specialisation of Health and Life Sciences (Abbey et al., 2008). However, HPCW aimed to develop activity across further sectors (Smart Specialisations) and a pan-Wales geography within a much wider partnership involving all universities in Wales. The research question of this study is to establish how the delivery of the initiative performed against this ambition and its stated aims, and to assess the contribution of the initiative to the Smart Specialisation agenda in Wales. 


\section{High Performance Computing Wales (HPCW)}

HPCW was established as a joint venture between six universities in Wales. It aimed to build upon pan-Wales strengths including ARCCA (Advanced Research Computing Cardiff) at Cardiff University, Visualisation capabilities at Bangor University, and Finite Element Analysis and Health \& Bioinformatics expertise at Swansea University. Each of these capabilities was aligned with local industrial applications through research collaborations involving existing facilities, subsequently identified as part of regional Smart Specialisations (EU, 2017). The initiative included expansion of the approach seen within the 'Blue-C' health informatics initiative based at the ILS in Swansea University’s Medical School (Abbey, Davies et al., 2008). Initially established as a three-year (extended to five-year) project with an original budget of $£ 40 \mathrm{~m}$ (TIP, 2015), HPCW was supported by co-investment from UK Government, European Structural Funds, the partner universities and the private sector. HPCW's core aim was to support the Welsh Government 'Key Sectors', identified as high-growth and knowledge-intensive where academia could collaborate with the private sector (WAG, 2010). This relatively broad approach would appear to be moving away from the Smart Specialisation approach championed by key figures (Morgan, 2013; Foray 2014), though HPC could be considered a 'general purpose technology' within the concept.

Of the original $£ 40 m$ budget, $£ 33 m$ was expended by its completion, with decommitment of remaining funds having been made following the mid-term review cited by Welsh Government (WG, 2017). A high-level options appraisal, based on Green Book appraisal approach (HMT, 2003, 2018) had identified the chosen option of a multi-site combined infrastructure and skills development approach. However, the technical implementation of the initiative had a nature similar in approach to that 
described by Peak, Guynes et al. (2011), and was defined in detail following a lengthy procurement process to select a technology partner.

\section{Case Review Approach}

HPCW was delivered as an initial project phase in 2010-2015, with scoping initiated during 2009. Led by public sector organisations, and delivered with a private sector technology partner, the initiative was developed using United Kingdom HM Treasury Green Book (HMT, 2003) principles, and based upon the 'ROAMEF’ cycle of: Rationale; Objectives; Appraisal; Monitoring; Evaluation; and Feedback (Fig. 1).

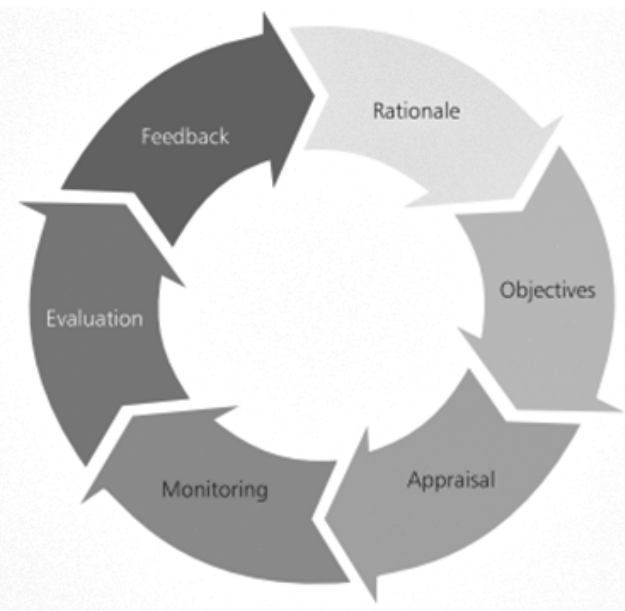

Fig. 1 ROAMEF Cycle, adapted from (HMTreasury 2003)

The case study therefore draws upon the ROAMEF cycle stages, using an approach (Fig.2) adapted from the work of Stake (1995), applied by Huxtable-Thomas et al. (2015) and subsequently used by Davies, Roderick et al. (2018) to examine other EU Structural Funds-supported projects.

A bibliographic review examines how the project fits within the context of the region's Smart Specialisations, together with perspectives from project phase evaluations and academic observations, applying the HM Treasury Green Book (HMT, 2003, 2018) and Magenta book (HMT, 2007) appraisal and evaluation approaches. 
As a project supported by the European Regional Development Fund (ERDF) (WEFO, 2013), HPCW was required to maintain detailed project records, as well as being subject to an independent end-project evaluation. These records, together with the original project business cases and supporting documentation provide the basis of this study.

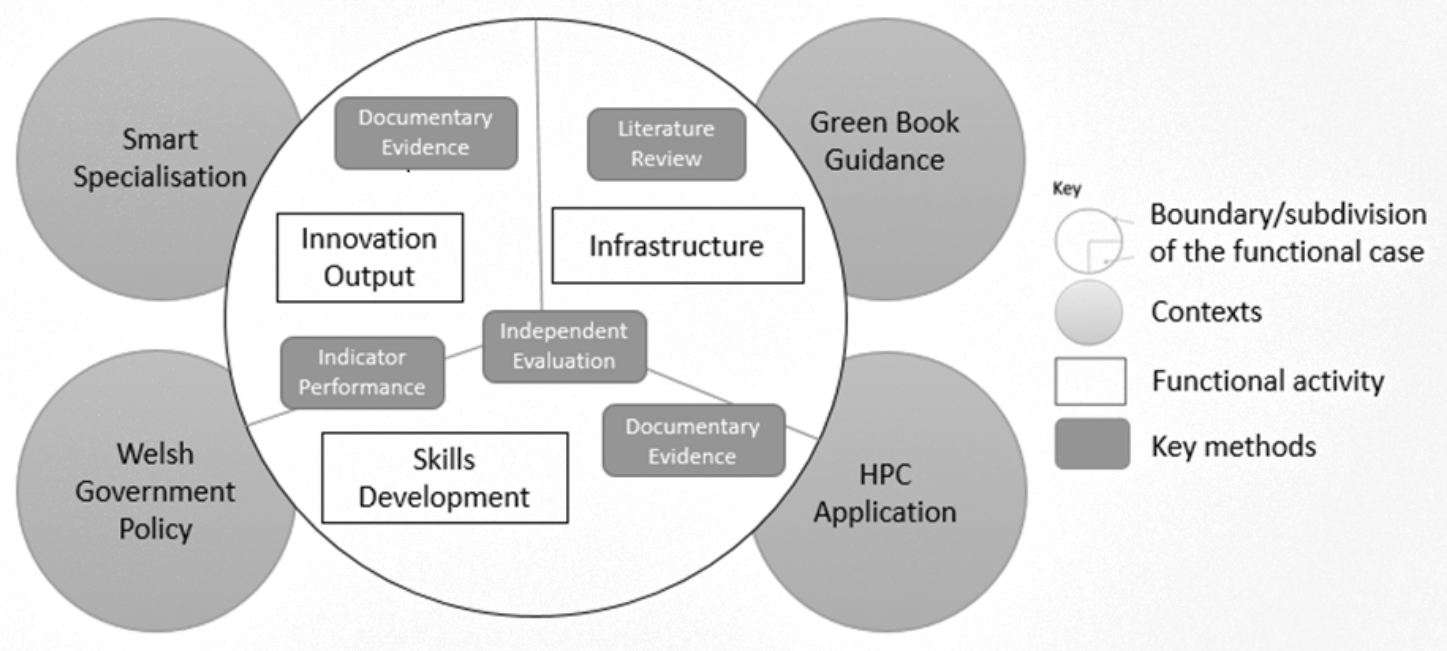

Fig. 2 HPC Wales Review Model

This study examines the initiative, starting from the initiative’s objectives, drawing upon the context of Smart Specialisation theory. The study’s mixed methods approach (Creswell and Clark, 2007) involves review of: the original HPC Wales project proposal in the context of regional economic development ambitions; observations from the independent end-project evaluation; and the initial project phase economic benefits using principles of HM Treasury guidance.

The review is structured upon the three HPCW components of R\&D infrastructure, job creation and innovation support, and skills development. This allows the relevant objectives and performance to be considered for each aspect of the initiative's ambitions, including their contribution to Smart Specialisation. 
Recognising HPCW's economic development purpose, the study applies the HM Treasury guidance to consider each of these components through a Net Present Value (NPV) for realised benefits, set against initiative costs to provide a combined Benefit/Cost figure for the overall initiative. HPCW was conceived as a long-term initiative, involving an initial time horizon of 10 years to build research and innovation capacity in academia and industry. This horizon also aligns with the timescale suggested for appraisal within the Green Book guidance (HMT, 2018) across the three HPCW components.

\section{Previous reviews and key observations}

The HPC Wales End-Project Evaluation (TIP, 2015) presents an essential reference for the case. The evaluation echoed themes drawn from HPCW's mid-point evaluation cited by Welsh Government (WG, 2017), presenting deeper consideration than presented elsewhere by Pugh, MacKenzie et al. (2018). The evaluation presented central recommendations of; more realistic targets and options appraisal at the outset; greater early engagement with beneficiaries; and longer-term framing of ambitions. Importantly, the detailed evaluation noted the skills-development activities of HPC Wales, along with the initiative’s longer-term ambitions.

At the core of the challenges described in the evaluation were the original setting of objectives and approach, which relates back to the early stages of the ROAMEF cycle (HMT, 2003, 2018). The mid-term evaluation cited by Welsh Government (WG, 2017) described how the initial appraisal had considered options in scope and delivery, though not regarding broader potential options for realising the targeted benefits. More recent guidance (HMT, 2018) provides a more structured approach for this stage through its Options Framework, giving early focus to this aspect of programme and project 
development. Used together with the recommended Five Case Business Case process (HMT, 2018), this provides a more robust framework for developing, delivering and learning from interventions.

A core recommendation of the End Project Evaluation (TIP, 2015) was to propose that future phases focus upon developing academic research capacity, which had been a strength of HPCW. This recommendation has been adopted and led to the development of 'Supercomputing Wales’, led by Wales’ research-led universities. Smart Specialisation theory relates to regional sectoral strengths that transcend academia and industry, which means HPCW contribution remains valid in this theoretical context. The following sections present findings relating to each of the three HPCW components.

\section{$R \& D$ Infrastructure}

The HPCW infrastructure (Fig. 3) composed of major 'Hub’ facilities in Swansea and Cardiff universities aligned to local research specialisms. 'Tiers' of smaller relatively homogenous systems connected by dedicated high-speed connections were established at the other universities across Wales (Aberystwyth, Bangor, Glamorgan, Glyndwr and Swansea Metropolitan). A combined computing power of 190 teraflops provided a significant capability, though split between sites to support users across the region (Clark, 2011). 


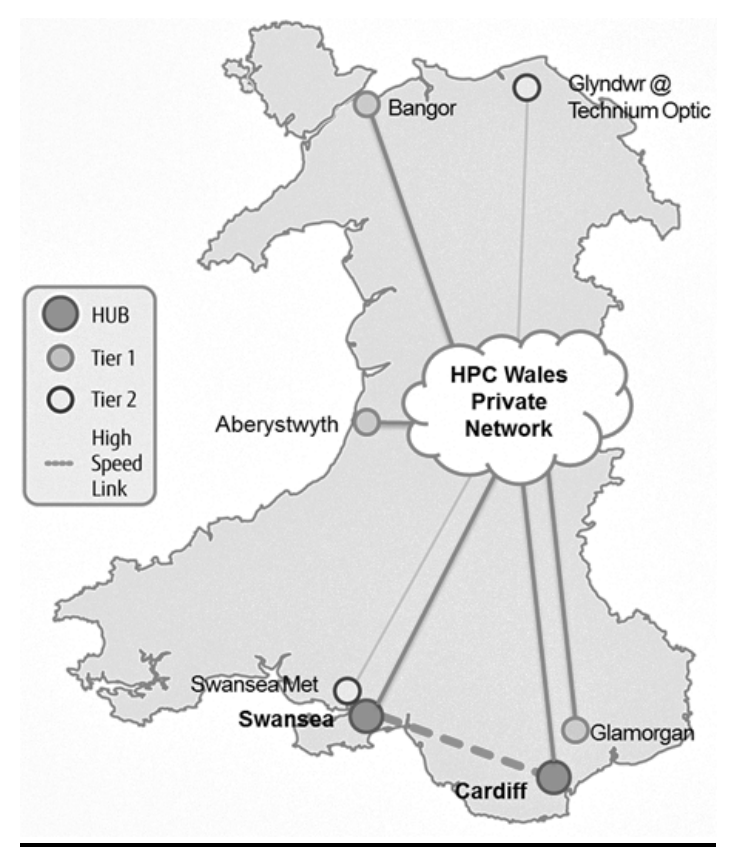

Fig. 3 HPCW Pan-Wales Infrastructure

The infrastructure itself represented an important part of the overall investment. The computer hardware has a limited lifecycle (it does though continue to be used in the transition period to Supercomputing Wales) that is broadly in line with the Green Book standard 10-year time horizon. While the infrastructure may have residual value it can, at least for the purpose of this review, be discounted as fully depreciated by the end of the initial project. However, the data centre infrastructure established for the distributed network remains, representing retained value and benefit, most notably at the Swansea Dylan Thomas Centre 'Hub’ site. Growing demand for such facilities, especially for those built to the environmental/financial (energy efficiency) performance standards of the HPCW sites suggests retention of value, which based on a retained approximately $70 \%$ of the initial value (using a standard depreciation cycle from the host universities financial policies), equating to $£ 1.4 \mathrm{~m}$ of benefit.

Delivery of research services to longer-term research projects has also provided benefit which can be quantified and related to the infrastructure. The enhanced regional research capacity, both in scope and scale of support provides clear additionality. Based 
upon benchmark costings of computation at the time (10p/core hour) this equates to $£ 8.1 \mathrm{~m}$ of resource into the Welsh higher education community during the period to mid2015. The facilities continue to be used by both academia and industry, but as these data are unavailable, this value is capped at the end-project figure.

\section{Job Creation and Innovation Support}

The HPCW infrastructure was supported by a team of 18 HPC specialists, composed of system administrators and outreach officers supporting academic and industrial users in the scoping, development and delivery of projects. This activity initially targeted the engagement of 550 companies, and the creation of 400 jobs. However, these targets were revised to 300 companies and 200 jobs respectively alongside decommitment of a portion of the initial funding, following the mid-term project evaluation (TIP, 2015). The most readily quantified economic benefit of the innovation activity was through support in the creation of new employment. Evidence supplied through ERDF funding claims (WG, 2019) indicated that there were 170 jobs created over the project period. Projection of benefits caps this performance at this project end level. This is significantly below the initial ambition to create 400 jobs, which the mid-term evaluation identified as over-ambitious. However, the end-project evaluation noted that the performance against the revised target was still significant "in spite of the challenging economic conditions”, i.e. a global economic recession (TIP, 2015).

Echoing the experience of centres in Pittsburgh (PSC, 2011) and Korea (Kim, Lee et al., 2010), most of the HPCW job creation was within supported enterprises outside the HPCW facilities.

When calculating economic impact of this employment benefit, a 50\% adjustment has been applied to factor additionality allowing for potential deadweight, 
displacement/substitution and leakage effects. This value is based on levels found for similar projects through ERDF Programme-level research (Oldbell3, 2008). A quantification of employment benefit can then be provided by factoring a salary/wage value of $£ 24,550$ per employee, i.e. job created (based on a sector relevant average in the region at the time). This is then applied with a typical employment multiplier of 1.5, though noting that context-specific research suggests for similar projects, by nature and location, this value may be closer to 1.66 (Oldbell3, 2008). It should be noted though that only jobs created are included in this assessment, excluding protection of existing jobs, since number of jobs created was not an ERDF indicator for the project and such data had not been recorded.

Using the logic presented above with the profile of HPCW job creation figures presents a contribution of approximately £19m (5yrs project end) / £39m (10-year horizon) of benefit through employment impacts. In addition, HPCW reported $£ 2.4 \mathrm{~m}$ of investment attracted into R\&D investments such as research scholarships which do not feature as part of job creation, for they provide studentship stipends rather than wages. The job creation impact has been noted by Pugh, MacKenzie et al. (2018), though without any contextual information or comparison of this performance to a relevant benchmark. Their observations are also not nuanced by the deeper discussion in the independent end-project evaluation or the broader available project and programme data (WG, 2019). Their observation is based on a 'cost per job’ perspective using initial funding envelope and targets, rather than actual out-turn of both jobs created and relevant expenditure.

To provide relevant context, when considered amongst the other concurrent major ERDF projects (£10m+ grant) 'Priority 1' (Knowledge Economy development), this provides a comparatively more balanced perspective when considering either ERDF 
grant or total public investment, as shown in Fig.4 below. Coupled with the infrastructure legacy which does not feature for most comparator projects (which are purely revenue activity) and the blended ERDF/ESF nature of activity, this does at least call for a more comprehensive evaluation, reflecting all objectives/benefits, as per the Green Book guidance (HMT, 2003, 2018).

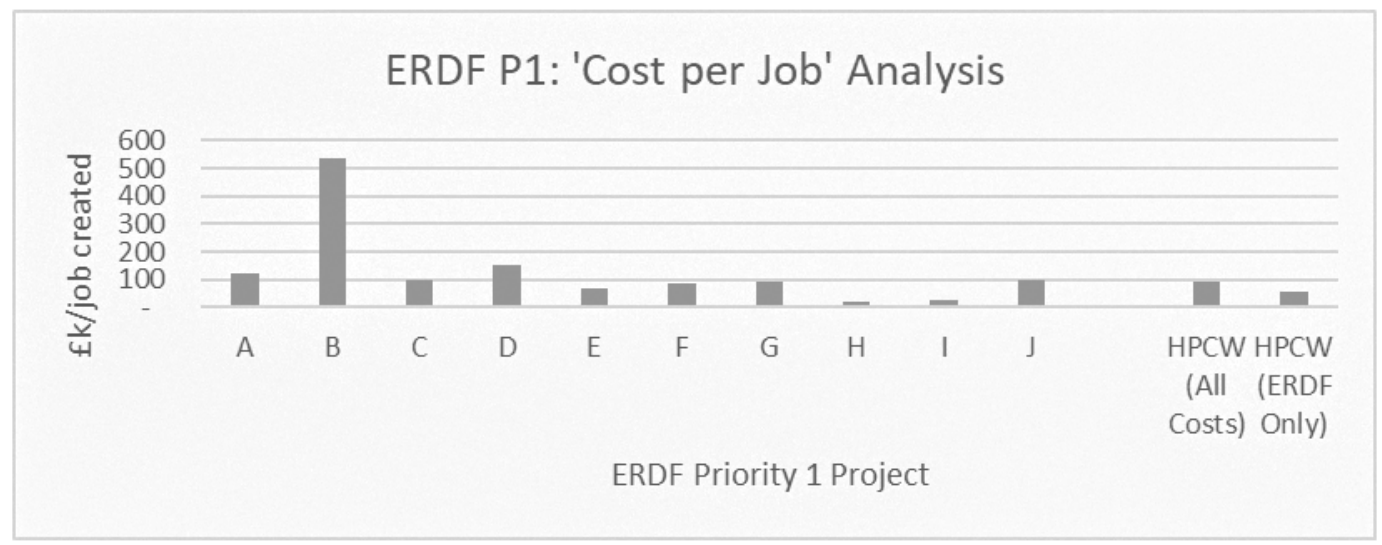

Fig.4 'Cost per Job' Project Comparison

Job creation is an important measure, however it is accompanied by a broader range of input, output and outcome indicators (OECD, 2005; WEFO, 2009). During delivery, HPCW reported 116 collaborative projects, attraction of £3.8m additional investment into R\&D activities, and supported development of 537 new products, processes and services. Furthermore, noting the timescales involved in commercialisation of research output, this may suggest further potential benefit beyond the project period.

Outside of the industrial innovation scope, the contribution of HPCW to new knowledge generation was captured. This included HPCW activity contributing to 166 journal publications, 108 conference proceedings and papers, and 85 studentships (TIP, 2015). This contribution became an important underpinning for what became Supercomputing Wales, effectively implementing the end-project evaluation's recommended HPCW 'phase 2'. 


\section{Skills Development}

HPCW initially aimed to provide skills development for 2,000 participants through 124 workshops delivering five sector-specific (Smart Specialisation) online courses. This was re-profiled following the mid-term evaluation to give greater emphasis to the number of courses and workshops, with a target of 1,960 participants (WG, 2019). This activity formed a significant part of HPCW delivery and was provided through a dedicated skills academy delivering training across academia and industry. Courses included both accredited (undergraduate and postgraduate level) and non-accredited (workshops / continuing professional development) provision. During the project, 1,622 individuals were involved in training with 459 gaining formal qualifications as a result. Data collection was ongoing until the end of the project, with it noted that due to the timescales of accredited awards, some project performance would fall beyond the project end date and would not have been included in figures reported at the time. In the context of this case study, the economic impact in both immediate and longerterm of this aspect of HPCW is difficult to quantify without further data. Therefore, for the purposes of this review, the Skills Development (cross-fund flexibility ESF) component is excluded, essentially taking these as benefits quantified by a 'Willingness to Pay’ approach offsetting the associated investment. This approach is in line with the relevant guidance for such circumstances (HMT, 2003, 2018). As the project has delivered well against these targets, this approach is both pragmatic and reasonable. The additionality of this activity and its benefit can also be considered as high, recognising continued calls for HPC skills development (EU, 2013a). 


\section{Total Benefits (NPV)}

Summarising the benefits presented above for each of the components and applying a discount rate of 3.5\% (HMT, 2003, 2018) results in the total benefits shown in Table 1 below;

\begin{tabular}{|l|l|}
\hline Benefit & Value \\
\hline Long-term infrastructure & $£ 1.4 \mathrm{~m}$ \\
\hline Research Activity & $£ 8.1 \mathrm{~m}$ \\
\hline Employment Impact & $£ 19 \mathrm{~m}$ (5years) £39m (10 years) \\
\hline $\begin{array}{l}\text { Investment Levered } \\
\text { (Innovation Scholarships/Projects) }\end{array}$ & $£ 2.4 \mathrm{~m}$ \\
\hline Project Income (Private Sector) & $£ 1.2 \mathrm{~m}$ (at project end) \\
\hline Skills Investment Impact & (excluded from this analysis) \\
\hline
\end{tabular}

Table 1. HPCW Benefits

\section{Benefit/Cost}

HPCW costs are taken as being the total public sector cash investment, adjusted for the skills element of the project for which related benefits are excluded. The post-project phase is based upon a cost-recovery model which offsets running costs against income from services. Therefore, the Net Present Value (NPV) of HPCW costs are based upon the expended project phase funding from public sector sources set against total benefits. Total discounted public investment of $£ 27.13 \mathrm{~m}$, provides for NPV and benefit/cost as shown below across project phase and 10-year time horizons (Table 2);

\begin{tabular}{|c|c|c|}
\hline & 5-year horizon (project) & 10-year horizon \\
\hline $\begin{array}{c}\text { Total benefits 5yrs (all } \\
\text { funding) }\end{array}$ & $£ 32.1 \mathrm{~m}$ & $£ 52.1 \mathrm{~m}$ \\
\hline Total costs (all funding) & \multicolumn{2}{|c|}{$£ 27.13 \mathrm{~m}$} \\
\hline Net Benefits (all funding) & $£ 7.13 \mathrm{~m}$ & $£ 24.97 \mathrm{~m}$ \\
\hline Benefit/Cost Ratio (B/C) & 1.18 & 2.08 \\
\hline
\end{tabular}

Table 2. HPCW Benefits and Costs, by Time Horizon 
By comparison with this summary, the independent end-project evaluation (TIP, 2015) using a Gross Value Add (GVA) approach presented a B/C ratio of return of 2.1:1, based on employment at the level achieved by 2015, aligning with the value found in the alternative approach adopted in this paper. However, a further baseline of greater relevance in the context of the ROAMEF cycle is the original appraisal undertaken during business planning. While the mix/balance of activities realised differed from that envisaged, the overall level of benefit and benefit/cost (calculated from projected NPV) is broadly similar in the original appraisal's Base-High range of 1.78 to 2.66

Benefit/Cost ratio. This suggests that appraisal during planning had accurately projected the level of benefit, though not the balance of benefits by type.

\section{Conclusion}

The case has shown the potential impact of a significant IT infrastructure to support economic development, demonstrating the importance of initial project appraisal and project phase monitoring and evaluation. It has highlighted a number of issues relevant to academic and practitioner interests which address the research question.

\section{Theoretical Contributions}

From an infrastructure and innovation activity perspective, the case contributes that HPC infrastructure could be considered as a General Purpose Technology to support a range of Smart Specialisations, as per the concept described by academics (Foray, David et al., 2009) (McCann and Ortega-Argilés, 2015) and key organisations (EU, 2013; OECD 2013). It has also shown such infrastructure can support meaningful job creation.

In this regard it has reinforced the observations of positive experiences from other HPC centres and initiatives (Kim, Lee et al., 2010; PSC, 2011), and contributed by evidencing similar benefit in a Western European context. 


\section{Practical Contributions}

The case has shown that practice can be enhanced by application of the ROAMEF cycle, and has demonstrated the cycle's potential value for practitioners at all stages of an initiative. This is shown through learning informing subsequent phases, while project objectives and funding can be refined during delivery. For policy development it has also presented that infrastructure of broad appeal (General Purpose Technology) can potentially support a range of sectors and users, potentially reducing risk by supporting multiple Smart Specialisations.

\section{Future Research Directions}

A limitation of this work is its cursory consideration of the impact of the skills development activity. Together with the longer-term impacts of the initiative, this may provide an opportunity for a subsequent review if appropriate data can be collected. Furthermore, as a sizable and novel IT infrastructure initiative, HPCW also provides scope for review from a range of potential further perspectives, including for example IT service and project management. However, this case has presented that further reviews of this or other cases should be undertaken with appreciation of the original case purpose and evolving context of delivery.

\section{Acknowledgements}

The authors would like to extend their gratitude to the editors and reviewers whose insightful and constructive feedback added significantly to this work.

\section{Author Biographies}

Joe Flanagan is the architect of the 5 Case Model and the author of the international and UK guidance materials. He is also Chief Examiner for the Better Business Cases (BBC) Programme, a member of the BBC International Steering Committee, the BBC 
International Standards Board and the BBC Joint Management Board. He co-founded the Building Better Business Cases Network across the UK, and works with governments around the world developing and deploying the Model. He has been Director of Investment and Appraisal for the National Health Service (NHS) in Wales, where he supported the Welsh Government Finance Department. Joe has been a public servant for 43 years and supported schemes across a range of departments.

Dr Gareth Davies is an Associate Professor in Swansea University’s School of Management, with research interests in innovation management and regional economic development. He was seconded to support the Welsh Government’s Knowledge Economy Nexus review of academic-industrial links, and has since worked on projects around the world to develop science park and technology transfer models. He has also worked on a broad range of industry and government funded projects such as HPCW using disruptive technologies for partners ranging from micro-businesses through to major multinationals, across sectors from construction to creative industries. He also has practitioner interests, including recently with the Swansea Bay City Region Internet Coast City Deal, the AgorIP commercialisation initiative, and the Accelerate initiative.

Dr. Frederic Boy is an Associate Professor in Swansea University’s School of Management and a Visiting Research Fellow at the Department of Biomedical Engineering of University College London. His research interests include neuroscience, big data and innovation. He has worked on a range of multidisciplinary projects in academic, industrial and clinical contexts, with recent focus on big data analytics. Working with a range of international and local partners, his work has led to the founding of spin-out companies based on disruptive technologies.

Dr Daniele Doneddu is a Senior Lecturer at Swansea University’s School of Management. He has a multidisciplinary background spanning engineering, medical technology, innovation, economic development and IP. He has been involved in a range of academic - business collaborative Research, Industrial Research and Enterprise and Innovation projects at the life science-engineering interface, successfully managed EUfunded medium (£2m+) private-public RDI initiatives - and advised life science and diagnostic companies on IPR, technology and engineering. He has been PI and Co-I on a number of UK and EU-funded research grants, including EPSRC, InnovateUK, FSA, 
H2020 (FET, MSCA), and involved in programmes spanning research upskilling, doctoral training, technology development and societal challenges.

\section{References}

Abbey, J., et al. (2008). Vorsprung durch Technium: Towards a system of Innovation in Southwest Wales. Regional Studies 42(2): 281-293.

Aldag, J. E. (1989). The impact of supercomputers: Global, pervasive, positive, California, Sage.

Armbrust, M., et al. (2010). A view of cloud computing. Communications of the ACM 53(4): 50-58.

Bell, G. and J. Gray (2002). What's next in high-performance computing? Communications of the ACM 45(2): 91-95.

Brynjolfsson, E. and L. M. Hitt (2003). Computing productivity: Firm-level evidence. Review of economics and statistics 85(4): 793-808.

Clark, J. (2020, January 20). Welsh HPC grid project signs £15m deal with Fujitsu. Retrieved from https://www.zdnet.com/article/welsh-hpc-grid-project-signs-15m-deal-with-fujitsu/.

Cooke, P., \& Leydesdorff, L. (2006). Regional development in the knowledge-based economy: the construction of advantage. The Journal of Technology Transfer, 31(1), 5-15.

Compete. (2015 January 20) Making Impact: Annual Report 2014-15. Council on Competitiveness. Retrieved from https://www.compete.org/reports/all/2936

Creswell, J. W. and V. L. P. Clark (2007). Designing and conducting mixed methods research, California, Sage.

Davies, G. H., et al. (2018). Social commerce Open Innovation in healthcare management: an exploration from a novel technology transfer approach. Journal of Strategic Marketing: 27(4), 356-367.

Dillon, T., Wu, C., \& Chang, E. (2010, April). Cloud computing: issues and challenges. In 2010 24th IEEE international conference on advanced information networking and applications (pp. 27-33). IEEE.

Dongarra, J. J. and A. Van der Steen (2012). High-performance computing systems: Status and outlook. Acta Numerica 21: 379-474.

E Gigler, B. S., Casorati, A., \& Verbeek, A. (2018). Financing the Future of Supercomputing: How to Increase Investment in High Performance Computing in Europe. European Investment Bank.

Etzkowitz, H. (1998). The norms of entrepreneurial science: cognitive effects of the new university-industry linkages. Research Policy 27(8): 823-833.

EU (2013a May 2013). Conclusions on 'High Performance Computing: Europe's place in a Global Race' Commission of the European Union, Retrieved from https://www.consilium.europa.eu/uedocs/cms_data/docs/pressdata/en/intm/137344.pdf

EU (2013b May 2013). The Goals of Smart Specialisation. European Commission. Retrieved from ftp://139.191.159.82/pub/EURdoc/JRC82213.pdf 
EU (2015 September). High Performance Computing in the EU: Progress on the Implementation of the European HPC Strategy. European Commission. Retrieved from https://ec.europa.eu/digital-single-market/en/news/study-high-performance-computing-euprogress-implementation-european-hpc-strategy-final-report

EU (2017 April). "Wales Smart Specialisations." European Commission, Retrieved from http://s3platform.jrc.ec.europa.eu/regions/UKL/tags/UKL.

Ezell, S. and R. Atkinson (2016 April). The vital importance of high-performance computing to US Competitiveness, Information Technology \& Innovation Foundation., Retrieved from http://www2.itif.org/2016-high-performance-computing.pdf

Foray, D. (2014). Smart specialisation: opportunities and challenges for regional innovation policy, London, Routledge.

Foray, D., et al. (2009). Smart specialisation-the concept. Knowledge economists policy brief 9(85): p100.

Galán-Muros, V., et al. (2017). Nurture over nature: How do European universities support their collaboration with business?, The Journal of Technology Transfer 42(1): 184-205.

Hanna, N. K. (1993). The information technology revolution and economic development, Washington DC, The World Bank.

HMT (2003). The green book Appraisal and evaluation in central government: HM Treasury guidance. Stationery Office.

HMT (2007). The Magenta Book: guidance notes for policy evaluation and analysis. London: HM Treasury, Stationery Office.

HMT (2018). The Green Book: Central Government Guidance on Appraisal and Evaluation. HM Treasury, Stationery Office.

Holdren, J. (2016 July). National Strategic Computing Initiative Strategic Plan. The National Strategic Computing Initiative Executive Council. Retrieved from https://www.whitehouse.gov/sites/whitehouse.gov/files/images/NSCI\%20Strategic\%20Plan.pdf

Huxtable-Thomas, L., et al. (2015). Using a Mixed Method 'Petri-Dish' Diagram to Determine Complex Impacts of Leadership Development in Extant Entrepreneurs. 14th European Conference on Research Methodology for Business Management Studies: 218-224.

Indjikian, R. and D. S. Siegel (2005). The impact of investment in IT on economic performance: Implications for developing countries. World Development 33(5): 681-700.

Johnston, R. (1998). US export control policy in the high performance computer sector. The Nonproliferation Review 5(2): 44-59.

Kim, J.-S., et al. (2010). Economic value analysis of supercomputing service for small and medium-sized businesses. IE interfaces 23(4): 319-326.

Lee, L. and S. Christensen (1990). The North Carolina supercomputing center: a study of economic development impact. The International Journal of Supercomputing Applications 4(4): 3-8.

Malecki, E. J., \& Malecki, E. J. (1997). Technology and economic development: the dynamics of local, regional, and national change. New York: Longman Scientific \& Technical.Matteucci, 
N., et al. (2005). Productivity, Workplace Performance and ICT: Industry and Firm-level evidence for Europe and The US. Scottish Journal of Political Economy 52(3): 359-386.

McCann, P. and R. Ortega-Argilés (2015). Smart specialization, regional growth and applications to European Union cohesion policy. Regional Studies 49(8): 1291-1302.

McLoughlin, G. J. and I. F. Fergusson (2003 May). High Performance Computers and Export Control Policy: Issues for Congress, Retrieved from https://fas.org/sgp/crs/natsec/RL31175.pdf

Mcnamara, B. (1987). "The Mass Market for Supercomputing." International Journal of High Performance Computing Applications 1(4): 3-4.

Morgan, K. (2013). The regional state in the era of Smart Specialisation. Ekonomiaz 83(02): 103-126.

Mowery, D. C. and N. Rosenberg (1989). New developments in US technology policy: implications for competitiveness and international trade policy. California management review 32(1): 107-124.

OECD (2005). Oslo manual: Guidelines for collecting and interpreting innovation data. Statistical Office of the European Communities, Publications de l'OCDE. Retrieved from https://rio.jrc.ec.europa.eu/en/library/oslo-manual-third-edition

OECD (2013). Innovation-driven Growth in Regions: The Role of Smart Specialisation. Organisation for Economic Cooperation and Development. Retreived from https://www.oecd.org/sti/inno/smart-specialisation.pdf

Oldbell3 (2008 October). ERDF Business Survey, Final Rerport. Welsh Government, Welsh European Funding Office. Retrieved from https://gov.wales/sites/default/files/statistics-andresearch/2019-07/161005-evaluation-customer-engagement-business-start-up-projects-en.pdf

Peak, D. A., et al. (2011). Aligning information technology with business strategy: An action research approach. Journal of Information Technology Case and Application Research 13(1): $16-42$.

PSC (2011). Economic Impact of the Pittsburgh Supercomputing Center. Fourth Economy., Retrieved from https://www.psc.edu/images/sciBk/psc2013_peoplesciencecollaboration.pdf

Pugh, R., et al. (2018). From 'Techniums' to 'emptiums': the failure of a flagship innovation policy in Wales. Regional Studies 52(7): 1009-1020.

Raisinghani, M. S. (2015). An Interview With Dr. Raj Jain, Professor of Computer Science and Engineering at Washington University in St. Louis. Journal of Information Technology Case and Application Research 17(3/4): 172.

Rončević, B., et al. (2019). Go with the flow, Fakulteta za informacijske študije v Novem mestu, London, Vega.

Samih, H. (2019). Smart cities and internet of things. Journal of Information Technology Case and Application Research, 21(1), 3-12.

Sarkar, S., Bilau, J. J., \& Basílio, M. (2020). Do anchor infrastructures matter for regional Smart Specialisation Strategy? The case of Alentejo. Regional Studies, (1)1: 1-12.

Stake, R. E. (1995). The art of case study research, California, Sage.

Strohmaier, E., et al. (1999). The marketplace of high-performance computing. Parallel Computing 25(13-14): 1517-1544. 
Strohmaier, E., et al. (2005). Recent trends in the marketplace of high performance computing. Parallel Computing 31(3-4): 261-273.

Sultan, N. A. (2011). Reaching for the "cloud": How SMEs can manage. International journal of information management 31(3): 272-278.

TIP (2015 September). Final Evaluation of High Performance Computing Wales. The Innovation Partnership Ltd. Welsh Government., Retrieved from https://gov.wales/docs/wefo/publications/160314-hpc-report.pdf

WAG. (2004). A Winning Wales; The National Economic Development Strategy of the Welsh Assembly Government, Welsh Assembly Government

WAG (2010). Economic Renewal: a new direction. Welsh Assembly Government

WEFO (2009 May). ERDF Indicators, Definitions and Evidence Requirements. Welsh European Funding Office, Retrieved from https://gweddill.gov.wales/funding/eu-funds/20142020/wefo-guidance/index9ed2.html?lang=en.

WEFO (2013). European Structural Funds programmes 2014-2020, West Wales and the Valleys European Regional Development Fund Operational Programme. Welsh European Funding Office., https://gov.wales/west-wales-and-valleys-european-regional-development-fund-erdfoperational-programme-2014-2020

WG (2017). The final report of the Evaluation of ERDF Support for Businesses (2007-2013) Welsh European Funding Office. Retrieved from https://gov.wales/docs/wefo/publications/evaluation/171205-ex-post-evaluation-2007-2013final-report-en.pdf

WG (2019) EU Structural Funds programme 2007 to 2013: Outcomes, Welsh Government, Retrieved from https://gov.wales/eu-structural-funds-programme-2007-2013-outcomes 